\title{
The Morphosyntax of Negative Pronouns Constructions in Jordanian Arabic
}

\author{
Issa Abdel Razaq (Corresponding Author) \\ Department of English Language \& Literature - Isra University, P. O. Box- 22-23 - Pin Code Amman 11622, Jordan \\ E-mail: issa.abdelrazaq@iu.edu.jo \\ Mohammed Mahameed \\ Department of English Language \& Literature - Isra University, P. O. Box- 22-23-Pin Code Amman 11622, Jordan \\ E-mail: mmahameed67@yahoo.com
}

Doi:10.7575/aiac.alls.v.8n.3p.133

Received: 23/04/2017

URL: http://dx.doi.org/10.7575/aiac.alls.v.8n.3p.133

Accepted: 16/06/2017

\begin{abstract}
The main aim of this paper is to investigate the asymmetric distribution of negation strategies in verbless constructions in Jordanian Arabic and similar dialects. In particular, negative pronouns constructions present two major problems for analyses of sentential negation. The first problem lies in the use of the verbal negation strategy in such constructions although they are verbless. The second problem is the merger of subject pronouns that are clear maximal projections with the negative marker occupying the head of the negative projection. To solve these problems, the paper provides an analysis that is based on the morphosyntactic properties of negative pronouns as well as the discourse properties of the constructions in which they occur. To account for the merger between the pronoun and the head of the negative, the study demonstrates that such pronouns belong to the class of weak bound subject pronouns that undergo head movement to Neg to check and delete its uninterpretable [+D] feature. The proposed analysis treats negative pronouns constructions as topic-comment structures that involve a fronted DP followed by a complete string of predication. As such, the paper concludes that the use of the marked negation strategy is a natural outcome given the discourse properties associated with topic-comment constructions to which negative pronouns constructions belong.
\end{abstract}

Keywords: Arabic dialects, negation, negative pronouns, verbless sentences, topic-comment constructions

\section{Introduction}

This paper is mainly concerned with the distribution of negation patterns in verbless sentences in Jordanian Arabic (JA henceforth), especially negative pronouns constructions. Negative pronouns are complex forms that involve a pronominal element surrounded by the discontinuous negation marker ma-f. Such pronouns are found only in present tense predicational constructions of the type shown below.

$$
\begin{aligned}
& \text { 1a. l-walad ma-huu- } \int \text { mareeD } \\
& \text { the-boy NEG-he-NEG sick } \\
& \text { 'The boy is not sick.' } \\
& \text { b. Pente ma-ntii- } \int \quad \text { Deif } \\
& \text { you NOT-you-NEG guest } \\
& \text { 'You are not a guest.' }
\end{aligned}
$$

Negative pronouns constructions pose two major problems for analyses of sentential negation in Arabic. The first problem lies in the use of the verbal negation strategy in non-verbal constructions such as the negative pronouns constructions shown in (1a-b). In such constructions, the negation strategy one expects to find is the one used for nonverbal sentences. This is not the case, however. Studies on negation in Arabic divide sentential negation into verbal and non-verbal negation (Eid 1992; Fassi Fehri 1993; Shlonsky 1997; Brustad 2000; Benmamoun 2000; Ouhalla 2002; AlSarayra 2010; Al-Momani 2011; Aoun, Benmamoun and Choueiri 2010; Soltan 2014; Mohammad 2014; Benmamoun et al. 2014; Benmamoun and Al-Asbahi 2014; Al Zahrani 2015; Algryani 2015 among many others). The choice between negation strategies is dependent on sentence type, i.e., whether it is verbal or non-verbal. Whereas verbal sentences display the discontinuous negation strategy shown in (2a), verbless sentences display the independent negation strategy shown in (2b) below.

$$
\begin{aligned}
& \text { 2. Ali ma-jaa- } \int \text { mbaariћ } \\
& \text { Ali NEG-came.3ms-NEG yesterday } \\
& \text { 'Ali did come yesterday.' }
\end{aligned}
$$


3. l-walad mif mareeD

the-boy NEG sick

'The boy is not sick.'

The discontinuous negation strategy used in verbal sentences like (2a) involves two negative elements, i.e., the proclitic $m a$ and the enclitic $\int$, that attach to the verb in the pattern NEG-V-NEG. Meanwhile, the independent negation strategy is restricted to verbless sentences like (2b) where the two negation elements appear as one morpheme, i.e., mif, realized independently of the subject and the predicate.

However, the distinction between verbal and non-verbal negation seems to be problematic. That is, the discontinuous negation strategy is not strictly restricted to sentences including verbal predicates, the data from JA shows that it can also be used in verbless sentences. The fact that verbless sentences like (1) and (3) admit either strategy points to an optionality problem as it appears we are dealing with two different PF representations that are derived from the same Numeration (see Chomsky 1995). Optionality, if true, is not tolerated in a system that is built on transderivational economy like the MP. Such an issue has always been overlooked in studies dealing with negation on Arabic (Eid 1992; Fassi Fehri 1993; Shlonsky 1997; Brustad 2000; Benmamoun 2000; Aoun, Benmamoun and Choueiri 2010; Soltan 2014; Mohammad 2014; Benmamoun et al. 2014; Benmamoun and Al-Asbahi 2014; Al Zahrani 2015; Algryani 2015). The majority of these studies focus on other interesting areas such as the interaction between tense, negation and the predicate in verbal non-verbal constructions. This study deals with the optionality issue and attempts to provide an in depth analysis in which optionality is taken to indicate that two types of constructions are involved.

The second major problem presented by negative pronouns constructions is the odd merger between a head and a maximal projection, namely the negative head and the subject pronoun, spelled out ma-ntii- $\int$ in (1a) and ma-huu- $\int$ in (1b). The standard assumption inspired by the influential work of Benmamoun (2000) on negation in Arabic and the works that followed is that only heads, such as verbs, can move and merge with negation. It will be demonstrated, however, that categories other than heads can also move to and merge with negation. Out of such categories, subject pronouns will be the main concern throughout this study. The fact that subject pronouns can comfortably merge with negation in verbless sentences casts doubt on the limitation of the head-movement assumption. To overcome this problem, Aoun et al. (2010), Soltan (2014) and Benmamoun et al. (2014) propose a morphological approach where subject pronouns in such constructions are said to incorporate into the negative head in the post syntactic component. Although this approach is on the right track, it leaves many questions unanswered, particularly questions about the syntactic status of the pronoun merging with negation, operations responsible for this merger, and whether or not this merger takes place in the syntax. This study attempts to provide an overall analysis for negative pronouns constructions based on the morpho-syntactic properties of such pronouns and their interaction with negation.

The sections of this study are organised as follows. Section (2) presents an overview of negation strategies used in verbless sentences and brings into light asymmetries found in the distribution of negation strategies in such constructions. Section (3) looks into the syntax of sentential negation in Arabic. It is divided into two subsections. The first subsection deals with negation in verbal sentences and lays out the main assumptions of the analysis developed in this study. The second subsection investigates negation in verbless sentences and discusses the problems posed by negative pronouns constructions. In section (4), I propose an analysis for negative pronouns based on their morphological make up and syntactic behaviour in the constructions where they occur. Section (5) continues with the analysis and settles the issue concerning the structure of negative pronouns constructions as a whole. Section (6) is the conclusion.

\section{Negation in verbless sentences: an overview}

Verbless sentences are present-tense predicational sentences that contain only a subject and a predicate. Like other varieties of Arabic, JA shows no copula in present tense predicational sentences. Only the subject and the predicate appear in this type of sentence. The predicate may be a nominal phrase (4a), an adjectival phrase (4b), or a prepositional phrase (4c).

$$
\begin{aligned}
& \text { 4a. Pente Deif lyoum } \\
& \text { you guest today } \\
& \text { 'You are a guest today.' } \\
& \text { b. dar-na gadeemeh } \\
& \text { house-our old } \\
& \text { 'Our house is old.' } \\
& \text { c. l-miftaah b-s-sayyara } \\
& \text { the-key in-the-car } \\
& \text { 'The key is in the car.' }
\end{aligned}
$$

In addition to simple predicational sentences, the other type of verbless sentence common in JA is the equative sentence. Equative sentences involve two DPs separated by a pronominal element in the fixed order DP PRONOUN $\mathrm{DP}$, as can be seen in the following examples ${ }^{\mathrm{i}}$. 


5a. 1-mudeer huwwa l-mas?ool
the-manager he the-responsible
'The principle is the one responsible.'

b. 1-banaat hinne Saћbaat 1-qaraar the-girls they owners the-decision

'The girls are the decision makers.'

The main difference between the sentences in (4) and (5) is the presence of the so-called copula pronoun (Eid1992, Shlonsky 2002, and Aoun et al. 2010) between the subject and the DP predicate. The use of the copula pronoun is restricted to present tense equative sentences and it can only take the form of a third person subject pronoun as shown in (5a-b). The fact that a pronominal form appears in equative sentences in Arabic instead of a verbal copula has always presented a problem for analyses. In this study, however, I will adopt the view advanced in Abdel-Razaq (2012) whereby copula pronouns are treated as subject pronouns; their function has nothing to do with the copula given that the language permits verbless sentences without a copula.

Concerning sentential negation, JA employs two different strategies that usually reflect the verbal non-verbal distinction between the two types of sentence in Arabic. Verbal sentences are negated via the verbal negation strategy, namely the discontinuous strategy, shown in the following examples. the-boy NEG-broke-NEG the-glass
'The boy did not break the glass.'
6a. 1-walad ma-kasari- $\int \quad$ 1-kaas
b. Pani ma-ba-fhammi- $\int \quad$ angleezi
I NEG-pres.understand.1s-NEG English
'I do not understand English.'

The discontinuous verbal strategy involves merger of the two negative elements $m a$ and $\int$ with the verb. The first part of this negative, $m a$, appears as a proclitic while the second part, $\int$, appears as an enclitic. The sentences in (6) show that both past and present tense verbs merge with negation and form the NEG-V-NEG pattern.

Verbless sentences, on the other hand, are usually negated via the independent strategy whereby the two elements of negation surface as one independent morpheme separating the subject and the predicate. This is illustrated in the examples in (7).

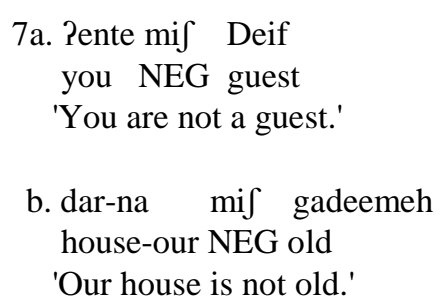

In addition to the independent strategy illustrated in the sentences above, verbless sentences may also be negated using the discontinuous negation strategy found in verbal sentences. The pronominal element that separates the subject and the predicate acts as a host for the discontinuous negative marker. Consider the sentences below.

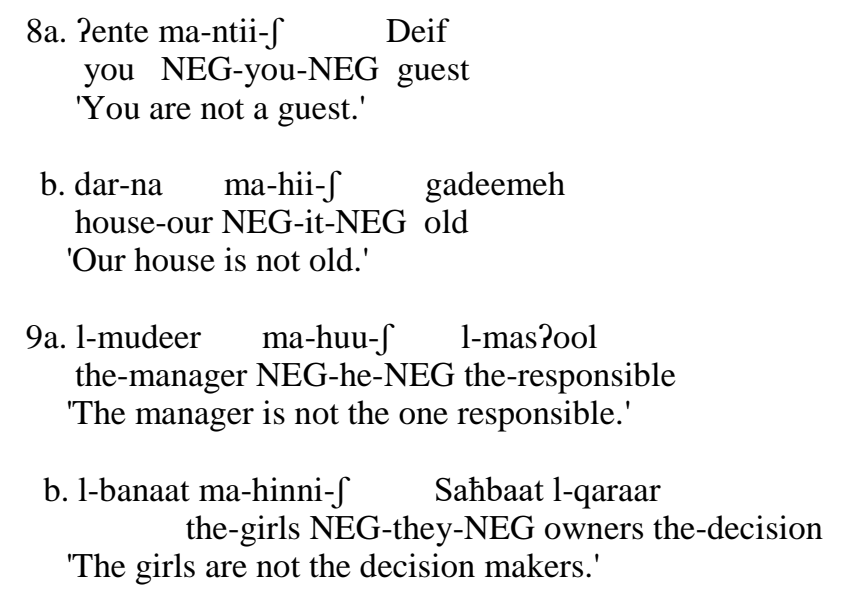

What we see in the sentences above is a pronominal form used with the standard verbal negation strategy to negate verbless sentences. Merger of the pronoun with the discontinuous negative results in the pattern NEG-PRON-NEG, that 
is reminiscent of the NEG-V-NEG form found in verbal sentences. What this suggests is that the syntactic behavior of these pronouns in relation to negation in such constructions is similar to the behavior of verbs in verbal sentences.

The distribution of negation patterns above gives rise to two major problems that deserve further careful investigation. First, the fact that verbless sentences maybe negated by either the independent negation strategy or the split negation strategy means that the distinction usually made between verbal and non-verbal negation (Eid 1992, Shlonsky 1997, Brustad 2000, Benmamoun 2000, and Aoun et al. 2010 among many others) does not strictly correspond to the standard distinction between verbal and verbless sentences. Whether or not optionality is at stake is an issue that needs to be settled. This study attempts to provide a syntactic analysis that explains (the apparent optionality) in such constructions while taking into account discourse properties that may affect the choice between negation strategies.

The second problem concerns the merger between what appears to be subject pronouns and the split negative used with verbal negation. Syntactically, the pronoun in such constructions displays a behaviour that is similar to the behaviour of verbs in verbal sentences. In addition to appearing between the subject and the predicate, the pronoun acts as a host for the two negative elements and shows full agreement with the left-most DP. This phenomenon is interesting in many respects. First, the function of such a pronoun as a host calls into question the syntactic status of elements that can merge with negation. Thus far, we have seen verbs and subject pronouns merge with negation. In the following sections, I will show that other XP categories can also merge with negation. In this respect, the widely held assumption that negation involves head movement (Benmamoun 2000, Aoun et al 2010, Mohammad 2014) must be modified in order to account for the facts presented here.

On the other hand, the fact that this pronoun is identical to subject pronouns raises two further questions. The first question is to do with the left-most DP and whether or not it is the canonical subject in this type of construction as is usually assumed (Eid 1992, Benmamoun 2000, Shlonsky 2002, Al-Momani 2010, Aoun et al. 2010). The second question is to do with the nature of the construction in which the (marked) verbal, rather than the (unmarked) independent negation strategy is used and whether the use of this strategy is linked to some other factors external to syntax. In what follows, I discuss these issues first and return afterwards to the issue of optionality.

\section{The syntax of sentential negation in Jordanian Arabic}

The main aim of this section is to provide a syntactic analysis for sentential negation in verbless sentences in JA. The first step in this analysis is to examine sentential negation in verbal sentences, which will bring up issues that will be crucial for the discussion ahead. This task is carried out in the next subsection.

\subsection{Verbal Negation}

Past and present tense verbal sentences involve the use of the discontinuous negation strategy. In sentences (10) and (11), the verb appears surrounded by the proclitic $m a$ and the enclitic $\int$ in the sequence [NEG-V-NEG].

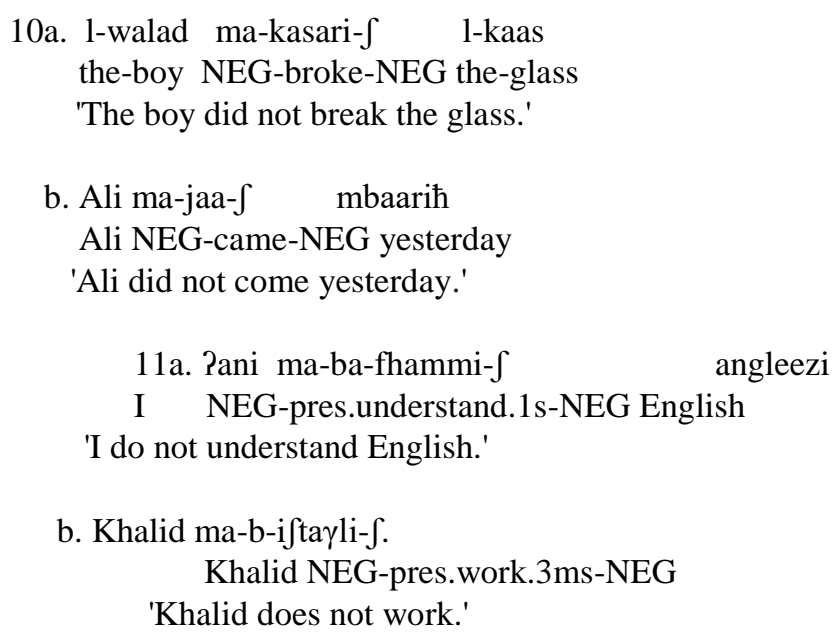

In past tense sentences, the verb always merges with negation in JA as the examples in (10a-b) show. To account for this merger, let us follow the analysis proposed in Benmamoun (2000) and Aoun et al. (2010) for various Arabic dialects and see whether it extends to JA. According to Benmamoun and Aoun et al., merger between past tense verbs and negation results from verb movement to negation on its way up to $\mathrm{T}$ in a structure where TP is higher than NegP. Movement of the verb to Neg ensures that the uninterpretable [+D] feature that Neg is assumed to have is checked and deleted. As for verb movement to $\mathrm{T}$, this movement is motivated by the assumption that past tense $\mathrm{T}$ in Arabic is specified for the verbal feature $[+\mathrm{V}]$, in addition to the nominal feature $[+\mathrm{D}]$, that needs to be checked and deleted against that of the verb. Given that NegP is located between VP and TP, the verb must move first to the negative head, adjoins to it and then continues its movement to T. To illustrate, consider the example in (10a) above and its simplified derivation represented in (12). 


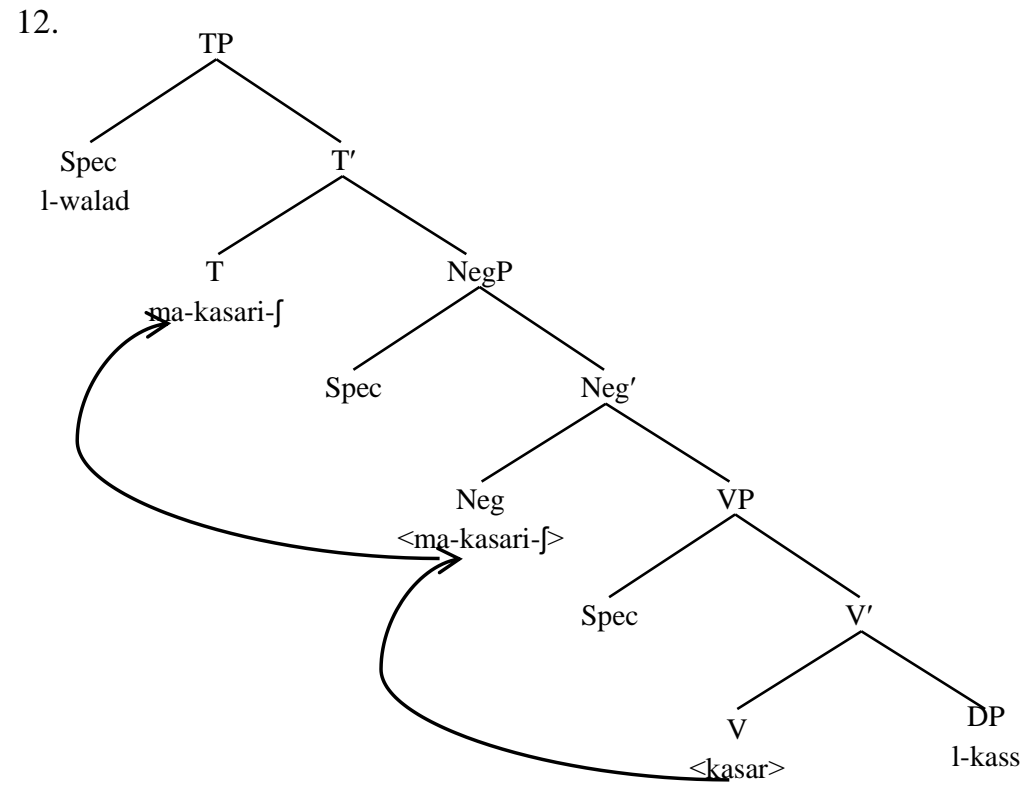

In the structure above, merger of the verb with the split negative marker results in the negative pattern NEG-V-NEG spelled out as ma-kasari-f 'did not break'. If on the other hand, the verb moves to T across the intervening Neg head, negation will appear after the verb in which case such constructions are ruled out as shown in the examples below.

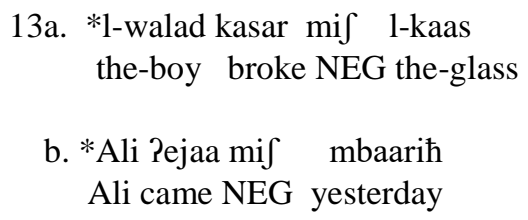

The reason why Neg blocks verb movement to $\mathrm{T}$ can be explained on the ground that the verb carries some feature that can check the categorial feature of negation; otherwise, there is no reason for negation to block verb movement to T. Following Ritter (1995), Benmamoun takes the person agreement feature on the verb to be the interpretable [+D] feature that qualifies the verb as a potential checker for the uninterpretable $[+\mathrm{D}]$ feature of negation. The sentences in (13) are ungrammatical because the $[+\mathrm{D}]$ feature of the negative head is not checked by the verb that moves across to T.

Concerning present tense sentences like (11a-b), these pattern with past tense sentences in that the verb always merges with negation in JA. However, the feature specification of present tense $\mathrm{T}$ differs from that of past tense $\mathrm{T}$. That is, present tense $\mathrm{T}$ is specified for the nominal [+D] feature only. It is not specified for the $[+\mathrm{V}]$ feature that therefore triggers movement of the verb to $\mathrm{it}^{\mathrm{ti}}$. The verb moves only to Neg and merges with it, as shown in the following representation.

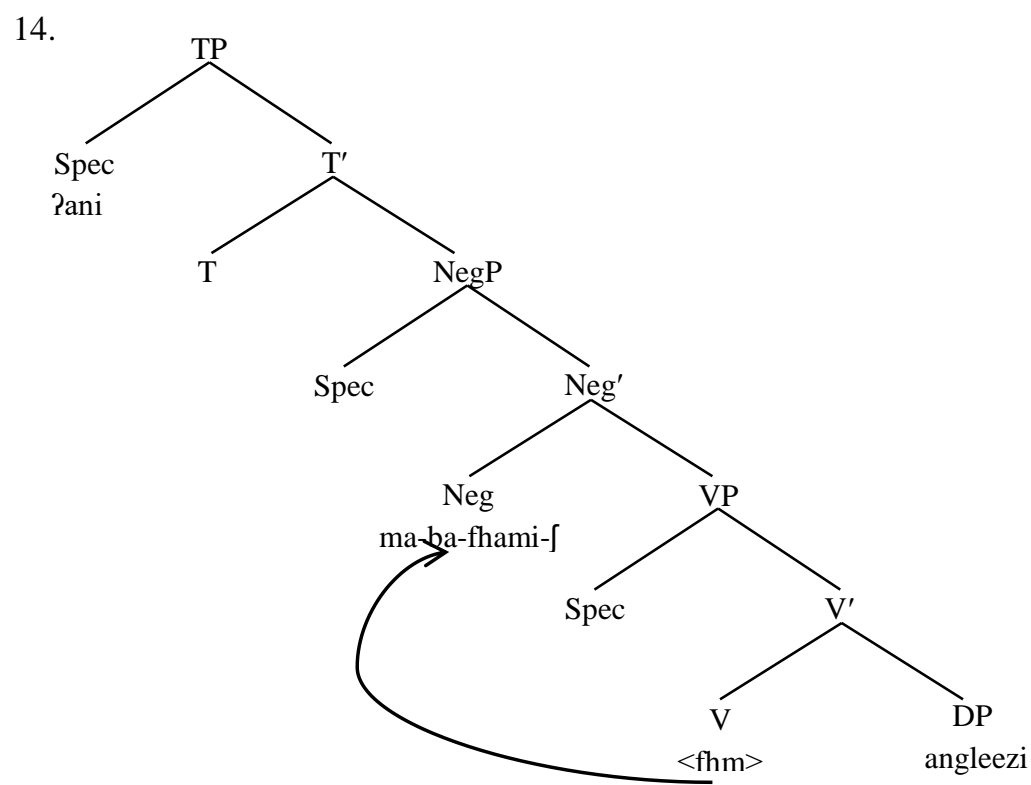


Verb movement to Neg in present tense sentences is motivated by the need of Neg to check and delete its uninterpretable categorial $[+\mathrm{D}]$ feature against the person feature of the verb. The pattern that results from this movement is the same as the one in past tense sentences, i.e., NEG-V-NEG.

As for future tense sentences, the situation is rather different. More precisely, future tense in JA is realized by the future particle $r a \hbar$ 'will.3ms' which precedes the verb. Negation in future tense sentences appears in a position before both the future tense marker and the verb, as can be seen in the following examples.

\author{
15a. maa-rah Paftari sayaara \\ NEG-FUT buy.1s car \\ 'I will not buy a car.' \\ b. haay l-m Gallme maa-rah temtahi-nna. \\ This the-teacher NEG-FUT examine-us \\ 'This teacher will not examine us.'
}

Unlike past and present tense sentences, future tense sentences show no sign of verb movement to negation. Instead, the verb seems to remain in situ preceded by the future and the negative markers, respectively. This situation is problematic for the analysis of Benmamoun (2000) and Aoun et al. (2010) adopted so far. In particular, the assumption that NegP is located below TP in the structure fails to capture the fact that negation occurs in a position before the future tense marker and the verb in the sentences above, and indeed in all future tense sentences in JA. In this instance, word order facts indicate that NegP cannot be lower than TP; it must be higher. The question that arises here is whether to abandon the lower NegP assumption in favor of an assumption that places NegP higher than TP. Additional negation facts from various other contexts provide strong evidence that the latter assumption is more plausible. I briefly discuss three of these contexts, namely Negative Polarity Items (NPIs), existential expletives, and auxiliary verbs contexts. These are illustrated in the following sentences respectively.

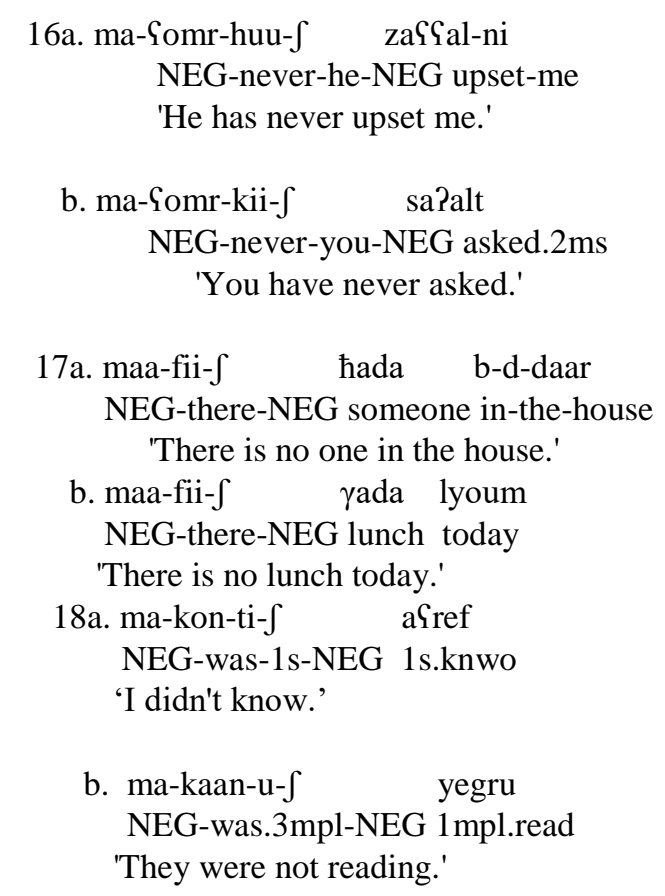

In sentences (16a-b), the NPI Somr merges with negation. Here, the licensing of the NPI Somr must take place within a NegP that is higher than TP. Under the lower Neg analysis, movement of the past tense verb to T across Neg results in ungrammaticality. Likewise, negation precedes existential expletives in (17a-b). As is well known, expletives are generated in Spec,TP in order to satisfy the EPP property of T. In the sentences in (17), the fact that the expletive is merged with negation can be captured only if we place NegP higher than TP. The third context involves negation merging with auxiliary forms of the copula kwn 'be' as in (18a-b). Such auxiliaries are base-generated in T. To account for sentences like (18), we have to position TP below NegP which allows the auxiliary to move to Neg and merge with the negative. The three contexts presented here, therefore, altogether provide the evidence necessary in favor of the placement of NegP above TP.

The facts from JA above are also found in other Arabic dialects. In addition to the Levantine varieties (Palestinian, Lebanese and Syrian Arabic), Egyptian and Gulf Arabic display the JA pattern of negation presented above. Consider the following examples from EA and $\mathrm{GA}^{\mathrm{iii}}$. 
19. miš ha-yib?a hilw Galay-ya

(EA: Brustad 2000)

NEG FUT-3ms.become pretty on-me

'It will not look good on me.'

20. maa-rah Paguul la-k Pana mann

(GA: Benmamoun et al. 2014)

NEG-FUT say.1s to-you I who

'I will not tell you who I am.'

In these sentences, negation occurs in a position before the future particle and the main verb. In EA, the future marker $\hbar a$ - surfaces as a prefix on the verb, both of which follow the negative morpheme miš. Similarly, the negative maa in GA precedes the future particle $r a \hbar$ and the verb. The lower NegP analysis predicts that negation should follow the future tense markers in EA and GA. This prediction is not borne out, however, as the above sentences show. These facts are best captured by positioning NegP above TP, not vice-versa. Altogether, the facts from JA and these dialects provide further empirical evidence for the present high NegP analysis.

Based on the facts and evidence presented above, the study proceeds with the more plausible assumption that NegP is higher than TP in JA. Returning to future tense sentences like (15), they can be assigned the structure shown in (21).

21.

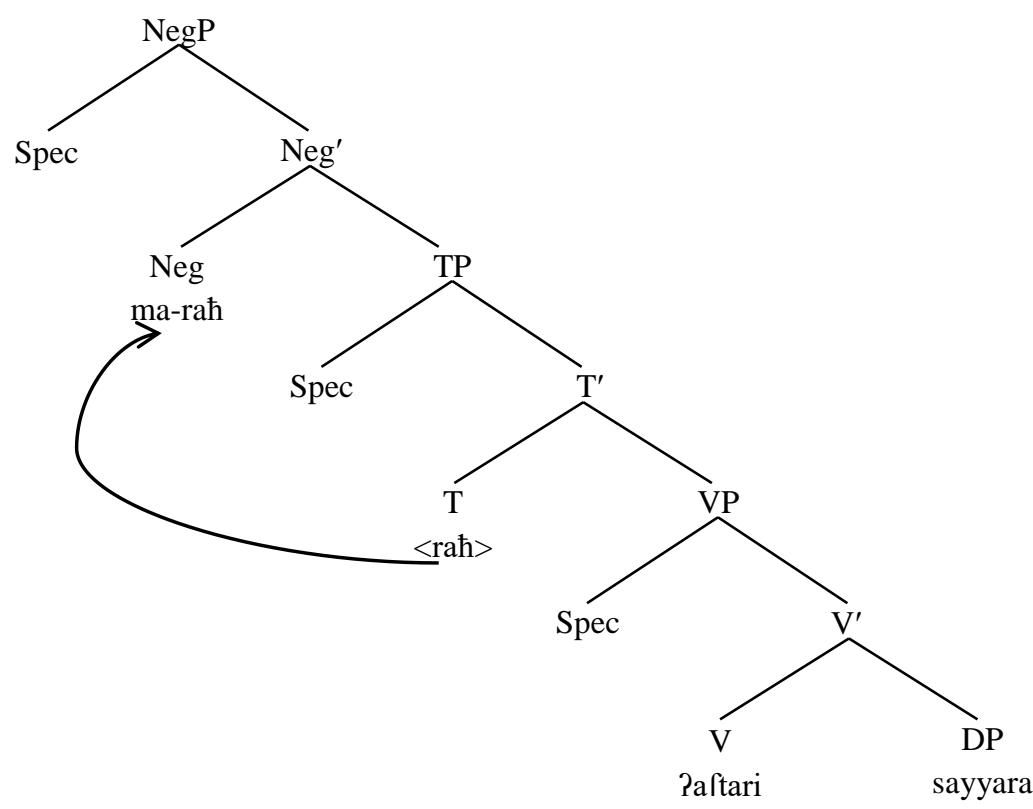

Under the structure in (21), the future particle $r a \hbar$ is base generated in T. This marker bears default phi features amongst which is the person feature ${ }^{\mathrm{iv}}$. It is therefore a closer goal in the sense of Chomsky (2000) to Neg than the verb. Hence, it undergoes movement to Neg to check and delete the [+D] feature, leaving the verb in situ. Movement of the future particle to Neg results in the pattern NEG-FUT, maa-rah, seen in the sentences above ${ }^{v}$. This way, the word order problem that we encountered earlier is avoided and the facts from future tense constructions are accounted for.

In light of the modified assumptions, let us now revisit sentential negation in past and present tense sentences presented earlier. In past tense sentences, verb movement to $\mathrm{T}$ is obligatory. That is, $\mathrm{T}$ carries the verbal feature $[+\mathrm{V}]$ that forces the verb to move to it. The verb then continues its movement up to Neg. This latter movement is motivated by the need of Neg to check its uninterpretable [+D] feature. Thus, sentences like (10a), repeated in (22a), now have the structure shown in (22b).

22a. 1-walad ma-kasari- $\int$

1-kaas

the-boy NEG-broke.3ms-NEG the-glass

'The boy did not break the glass.' 
b.

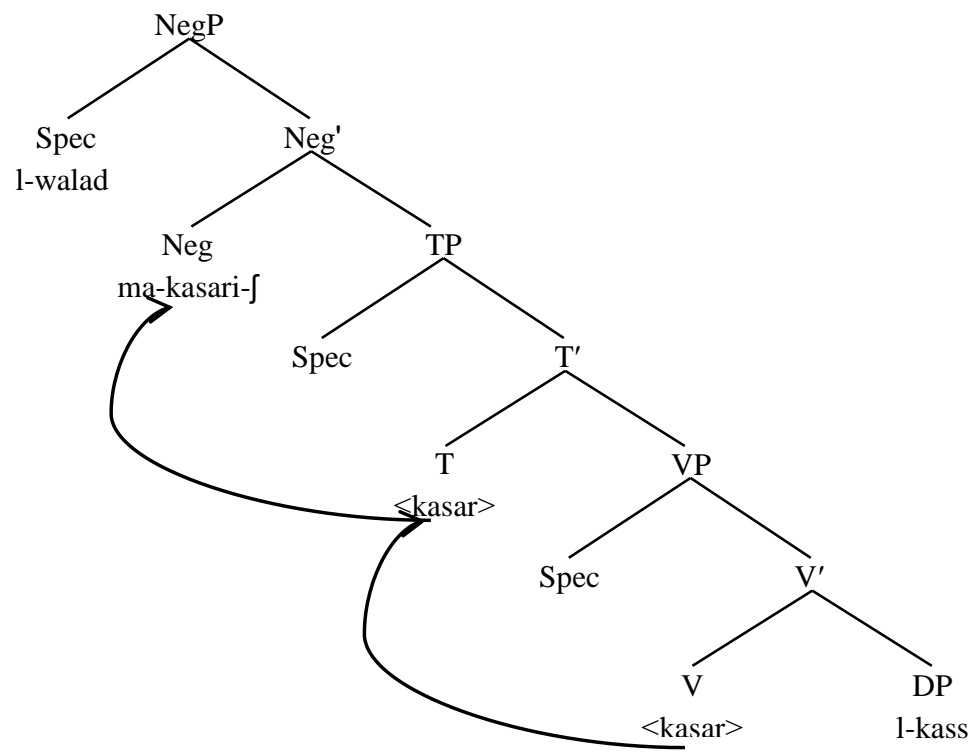

As for present tense sentences, they too involve a similar pattern of verb movement. The difference between past tense and present tense sentences boils down to the $[+\mathrm{V}]$ feature. Present tense $\mathrm{T}$ is not specified for this feature. Movement of the verb to T then is to merely avoid Minimality violations (Rizzi 1990, Chomsky 1995, 2000) since the verb cannot move across an intervening head like $\mathrm{T}$ on its way to Neg. As such, the new structure for present tense sentences like (11a), repeated in (23a), is given in (23b) below.

\section{3a. Pani ma-ba-fhammi- $\int \quad$ angleezi \\ I NEG-pres.understand-NEG English \\ 'I do not understand English.'}

b.

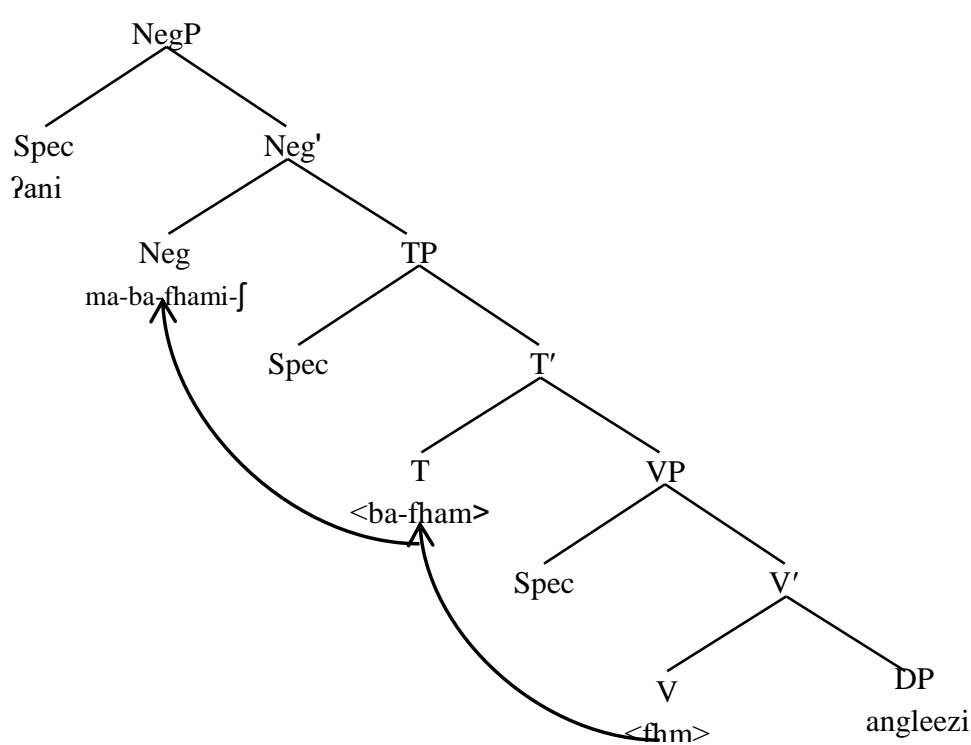

In the structure above, verb movement to Neg results in the checking and deleting of the [+D] feature of Neg. Notice that it is not the verb per se that checks the $[+\mathrm{D}]$ feature, rather it is the subject agreement features on the verb, specifically the person feature, against which the checking takes place. It is also noteworthy that verb movement in such contexts is an instance of head movement. Once the verb adjoins to the negative head, the pattern NEG-V-NEG surfaces at PF spelled out as ma-ba-fhammi-f.

Thus far, we have been concerned with the interaction between negation, tense and the verb, especially the location of NegP in relation to TP. We have concluded, based on empirical evidence, that NegP must be higher than TP. Pursuing the analysis, the other issue to be tackled at this juncture concerns the position of the subject with regard to sentential negation. As might be recalled, the subject precedes both the negative and the predicate in SV sentences as well as in verbless sentences. Building on the view that $\mathrm{NegP}$ is higher than TP, the fact that the subject precedes the negative indicates that the subject has moved from Spec,TP to a higher position. This raises two questions: one about the position to which the subject moves and another about the motivation for this movement. 
As for the first question, the most likely position that the subject moves to is the specifier position of NegP, given the $\mathrm{S}$ NEG V and the S NEG PRED order in verbal and predicational sentences, respectively. It can be then argued, theoretically, that movement of the subject to Spec,NegP is motivated by the need to satisfy a requirement of the negative head, such as the EPP. Such an argument is plausible, though not conclusive, and is in line with the recent extensions of the EPP (Chomsky 2000) to become a property of all core functional categories including C, T and $v$. For each of these categories, the EPP is satisfied by movement of a phrase to the specifier position of that category ${ }^{\mathrm{vi}}$. Pursuing this line of reasoning, we can add the functional category Neg to the list of functional categories that have the EPP property. The EPP property of Neg is satisfied by Internal Merge in the sense of Chomsky (2000) which involves movement of the agreeing DP to Spec,NegP. Like other functional categories, the EPP property of the Neg head, however, cannot trigger movement on its own. The Neg head must also have some independent feature along with the EPP. Recall that under the analysis presented here, Neg is said to have an uninterpretable categorial feature, namely the $[+D]$ feature. It seems natural to assume that it is this feature Neg has along with the EPP property that are responsible for movement of the subject to Spec,NegP.

In addition to the fact that the subject precedes negation in SV sentences and predicational sentences along with the theoretical argumentation above, empirical evidence that the subject is in spec NegP can be obtained from contexts involving negative subjects. In JA, the negative subject wala-NP cannot co-occur with the negative head in the same sentence. Consider the following cases:

$$
\begin{aligned}
& \text { 24a. wala hada Saahi } \\
& \text { NEG one awake } \\
& \text { 'No one is awake.' } \\
& \text { b. ma-hada- } \int \quad \text { Saahi } \\
& \text { NEG-one-NEG awake } \\
& \text { 'No one is awake.' } \\
& \text { c. *wala ma-hada- } \int \quad \text { Saahi } \\
& \text { NEG NEG-one-NEG awake }
\end{aligned}
$$

In (24a), sentential negation is warranted by the presence of the negative subject wala hada 'no one' while in (24b) it is

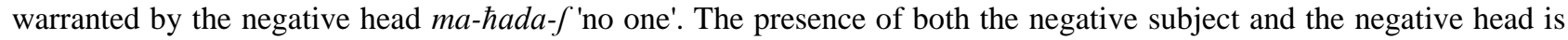
ruled out, as is the case in (24c). The examples here indicate that only one element can occur within the negative projection. Under the present analysis, sentences like (24a) provide direct evidence that the negative subject is in $\mathrm{Spec}, \mathrm{NegP}$, hence its presence in the negative projection is sufficient to obtain sentential negation.

Moreover, the view that the subject moves to $\mathrm{Spec}, \mathrm{NegP}$ is gaining extra support in recent studies on negation in Arabic (see Benmamoun et al. 2014, Benmamoun and Al-Asbahi 2014, Algryani 2015). In their study, Benmamoun and AlAsbahi (2014) propose that Spec,NegP is the default position for the subject in negative verbless sentences in various other dialects. Consider the following examples from San'ani Arabic and Moroccan Arabic in (25-26).

25. Pal-hadiiga miš haliya

The-garden NEG beautiful

'The garden is not beautiful.'

26. 1-weld maši hna

The-boy NEG here

'The boy is not here.'
(San'ani Arabic)

(Moroccan Arabic)

Like JA, San'ani and Moroccan Arabic verbless sentences have a fixed word order in which the subject comes first, followed by the negative particle and the predicate, as shown in the sentences above. To account for word order facts in these sentences, Benmamoun and Al-Asbahi argue that the subject is in the specifier position of NegP after its movement from the lower specifier position of TP.

To recap, the discussion above started with an analysis, adopted from Benmamoun (2000), for the syntax of sentential negation in verbal sentences in JA. While the adopted analysis accounts for some of the facts from past and present tense sentences, it runs into empirical problems when one examines negation in future tense sentences, NPIs, existentials and auxiliary verbs constructions. The discussion concluded that the facts from these constructions are best captured by locating NegP above TP, not vice versa. It was then demonstrated that the new analysis accounts for all the data from the various constructions in JA and other dialects considered so far. In the next subsection, the discussion continues with the syntax of sentential negation in verbless sentences.

\subsection{Non-verbal negation}

In this section, we turn our attention to negation in verbless sentences, particularly sentences involving negative pronouns. Studies dealing with negative pronouns (Eid 1992, Shlonsky 1997, Ouhalla 2000, Aoun et al. 2010, Soltan 
2014, Benmamoun and Al-Asbahi 2014, Benmamoun et al. 2014) have not yet settled the debate about the syntactic status of such pronouns and the overall structure in which they occur. One of the reasons that the debate is still ongoing is that these studies overlook the crucial difference between simple predicational sentences and sentences containing negative pronouns. The two represent two different types of construction and each type is associated with properties that are not found in the other. For instance, the fact that negative pronouns constructions include a subject pronoun has a dramatic effect on the syntactic status and on the complexity of the overall structure, unlike predicational sentences that involve only the subject and the predicate. Any analysis dealing with negative pronouns must, therefore, account for the difference between types of verbless constructions and for how this difference affects sentential negation.

For the present analysis, then, the best way forward is to take the distinction between types of verbless sentences into account. Starting with simple predication sentences, these involve a subject DP followed by either a nominal, adjectival or prepositional phrase predicate. In spite of the absence of a verbal predicate, these sentences are marked for present tense that therefore contain a TP in their structure ${ }^{\text {vii }}$. Following Aoun, et al. (2010), I take the structure for such constructions to be the simple subject predicate structure represented in the configuration below.

27.

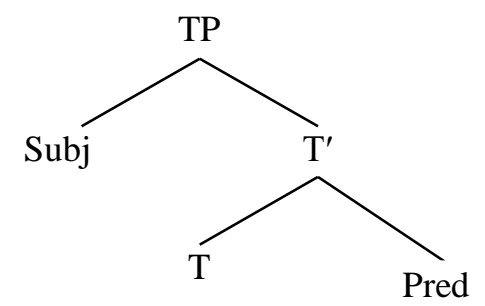

Concerning negation in simple predicational sentences, the strategy employed in this type of construction is the independent strategy whereby the two negative elements surface as one independent morpheme, namely mif, between the subject and the predicate. Under the analysis proposed earlier, NegP is located higher than TP. Thus, the syntactic structure for negative sentences like (28) might be represented in (29).

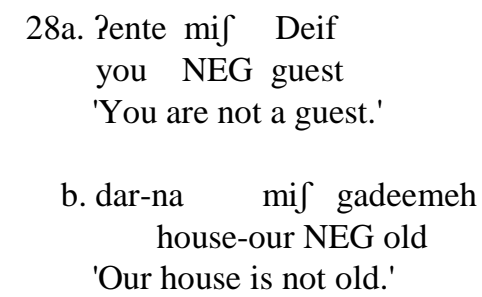

29.

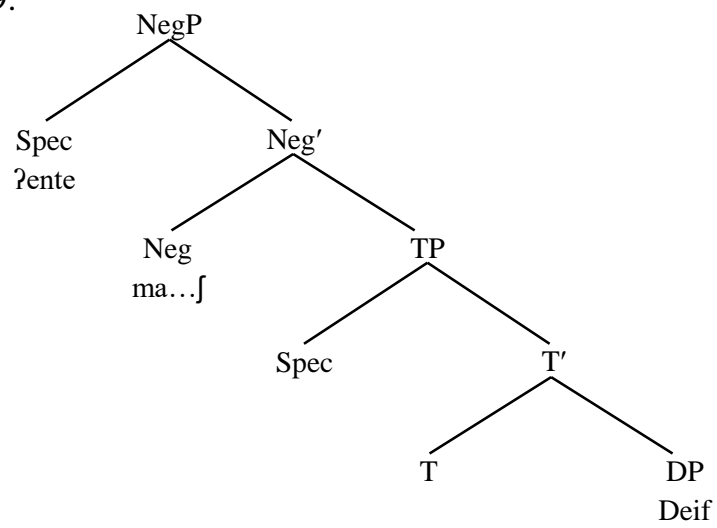

In this structure, the subject originates in the specifier position of TP. It then undergoes movement to Spec,NegP to satisfy the EPP requirement of $\mathrm{Neg}^{0}$. Movement of the subject in such sentences also results in the checking of the uninterpretable [+D] feature of Neg. Following Benmamoun (2000), the checking of this feature here is achieved through the Spec-head relation with the subject in Spec, NegP. After all syntactic operations have taken place, the two negative elements occupying the negative head fuse together and form the complex negative morpheme spelled out as mif. This way, the analysis does not only account for the use of the independent negation strategy but it also captures the word order displayed in such constructions. The analysis also predicts that sentences in which the subject remains in Spec,TP should be ruled out. This prediction is borne out as might be shown in the following examples. 


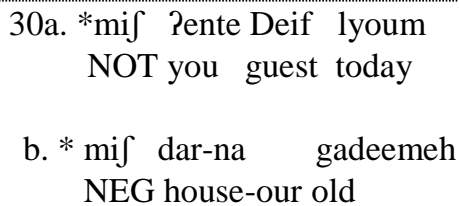

In (30) above, the subjects Pente 'you' in (30a)and dar-na 'our house' in (30b) remain in situ and do not raise to Spec,NegP. In this case, neither is the EPP property of Neg satisfied nor is the uninterpretable [+D] feature is checked, hence the ungrammaticality.

As for negative pronouns constructions, the cases presented in this study show that negative pronouns are compounds that clearly result from the merger of what seems to be subject pronouns with the split negative marker ma-f. To confirm that the pronoun in negative pronouns constructions is a subject pronoun, an independent examination of subject pronoun forms proves useful at this point. Indeed, the data shows that the class of subject pronouns in JA is almost identical to the ones that surface with negation in negative pronouns constructions. This is illustrated in the table below.

(31) Subject pronouns and their negative counterparts in JA

\begin{tabular}{lcc}
\hline & Subject pronouns & NEG-PRON-NEG \\
\hline $1 \mathrm{~s}$ & Pani & ma-nii- $\int$ \\
$1 \mathrm{pl}$ & Pehna & ma-hnaa- \\
$2 \mathrm{~ms}$ & Pinta & ma-ntaa- $\int$ \\
$2 \mathrm{fs}$ & Pinti & ma-ntii- $\int$ \\
$2 \mathrm{mpl}$ & Pinto & ma-ntuu- $\int$ \\
$2 \mathrm{fpl}$ & Pintin & ma-ntinni- $\int$ \\
$3 \mathrm{~ms}$ & huu & ma-huu- $\int$ \\
$3 \mathrm{fs}$ & hii & ma-hii- $\int$ \\
$3 \mathrm{mpl}$ & hummu & ma-hummu- $\int$ \\
$3 \mathrm{fpl}$ & hinne & ma-hinni- $\int$
\end{tabular}

The table above shows that each negative pronoun is a complex form that contains a pronoun surrounded by the discontinuous negative marker. The pronouns that appear inside the negative complex are almost the same as the independent subject pronouns, with minor phonological differences resulting from the merger with the negative. While the resemblance between the two pronominal paradigms above strongly suggests that negative pronouns contain a subject pronoun in their structure, it also eliminates the possibility that such pronouns are object pronouns. Functionally, object pronouns originate as DPs in the internal argument position, surface as clitics on verbs and prepositions, and have forms that are different from the ones shown in the table above. In addition, object pronouns cannot, and are not expected to, occur in verbless sentences of the type under study since such sentences contain only a subject and a predicate; whereas, subject pronouns can, and are expected to. Based on these observations, then, it is safe to confirm that the pronouns merging with the negative in verbless sentences are subject pronouns.

Given that negative pronouns are subject pronouns merged with the negative head ma... in the pattern NEG-PRONNEG, we must account for how such eccentric merger takes place. Syntactically, negative pronouns behave like verbs with regard to sentential negation. In addition to appearing between the subject and the predicate, they carry full agreement with the DP subject and merge with negation in a way similar to verbs in verbal sentences. The difference is, however, that negative pronouns are subject pronouns, i.e., maximal projections, merged with the negative head Neg ${ }^{0}$. Such behavior poses a serious problem for the original assumption made in Benmamoun (2000) whereby merger with negation is taken to be a head-movement process, as we have seen earlier in the cases of past and present tense sentences.

The head-movement assumption is further weakened when one examines closely the behaviour of other categories, beside subject pronouns, and how they interact with negation. The data from Jordanian shows that there are other categories which can also merge with negation despite the fact that they are not heads. Consider the following examples.

$$
\begin{aligned}
& \text { 32a. ma-fii- } \int \quad \text { mufkele } \\
& \text { NEG-existential-NEG problem } \\
& \text { 'There is no problem.' } \\
& \text { b. ma-maS-huu- } \int \quad \text { maSaari } \\
& \text { NEG-with-him-NEG money } \\
& \text { 'He has no money.' }
\end{aligned}
$$


In the sentences above, both the existential expletive fii 'there' (32a) and the PP-clitic mas-huu 'with-him' (32b) are merged with negation in the left-peripheral position. Both are cases of maximal projections merged with a head just like the case with subject pronouns. The facts here indicate that our analysis has to allow categories other than heads to merge with negation. The question is, however, whether we can maintain the head-movement assumption that we have adopted thus far. To deal with this question, and for the purpose of this study, I focus attention on the case of subject pronouns, though the proposed analysis has clear implications for the other categories that can merge with negation, too.

Subject pronouns and their merger with negation present a problem for analyses incorporating standard assumptions on head movement and phrase movement. Several views about this type of pronouns have been entertained in the literature on negation in Arabic. One of the earliest views is advocated in Eid (1992) who proposes an agreement analysis for such pronouns. More precisely, these elements are said to originate as AGR features in INFL that are then realized in the form of negative pronouns in the presence the negative in INFL. Such a view is based on a distinction Eid makes between the so-called copula pronouns and their negative counterparts, namely negative pronouns. Accordingly, negative copula pronouns differ from copula pronouns in their agreement system. While the former always agree with their subject in all phi-features including the person feature, the latter does not. As such, copula pronouns display an agreement pattern associated with NP agreement; whereas, negative copula pronouns display the pattern characteristic of subject-verb agreement, i.e., IP agreement, hence the agreement analysis for negative pronouns ${ }^{\text {viii }}$.

More recently, Aoun, Benmamoun and Choueiri (2010) reject the agreement analysis of negative pronouns ${ }^{\mathrm{ix}}$. Instead, they opt for the incorporation analysis and briefly argue that negative pronouns are subject pronouns incorporated into negation in the post-syntactic component. This type of analysis is extended in Benmamoun et al. (2014) to various Arabic dialects including Standard Arabic (SA), Moroccan Arabic (MA) and Egyptian Arabic (EA). The main motivation behind the incorporation analysis comes from an analogy in the behavior of the SA negative marker laysa and the negative pronouns in the dialects, both of which appear in present tense predicational sentences. To illustrate, consider the following SA examples with laysa and compare them with the negative pronouns constructions under study.

$$
\begin{aligned}
& \text { 33a. lays-uu hunaa } \\
& \text { NEG-3mpl here } \\
& \text { 'They are not here.' } \\
& \text { b. las-na fii l-bayt-i } \\
& \text { NEG-1pl in the-house } \\
& \text { 'We are not in the house.' }
\end{aligned}
$$

Notice that the negative laysa in the sentences above carries subject agreement just like the subject agreement that verbs carry in Arabic. Nevertheless, Benmamoun (2000) and Benmamoun et al. (2014) argue for the view that rather than a verb, laysa is a compound negative complex that contains the default negative particle in SA, namely laa, merged with a subject pronoun. Syntactically, laysa occurs in verbless sentences like (33) above where there is no verbal predicate (required) to merge with negation and tense. Since the subject pronoun is in the specifier position of TP which is, in turn, dominated by NegP, the subject cliticizes into the negative head in the post syntactic component. To give an example, consider the derivation Benmamoun et al. provide for the negative las-ta (NEG.2ms) diagramed in (34).

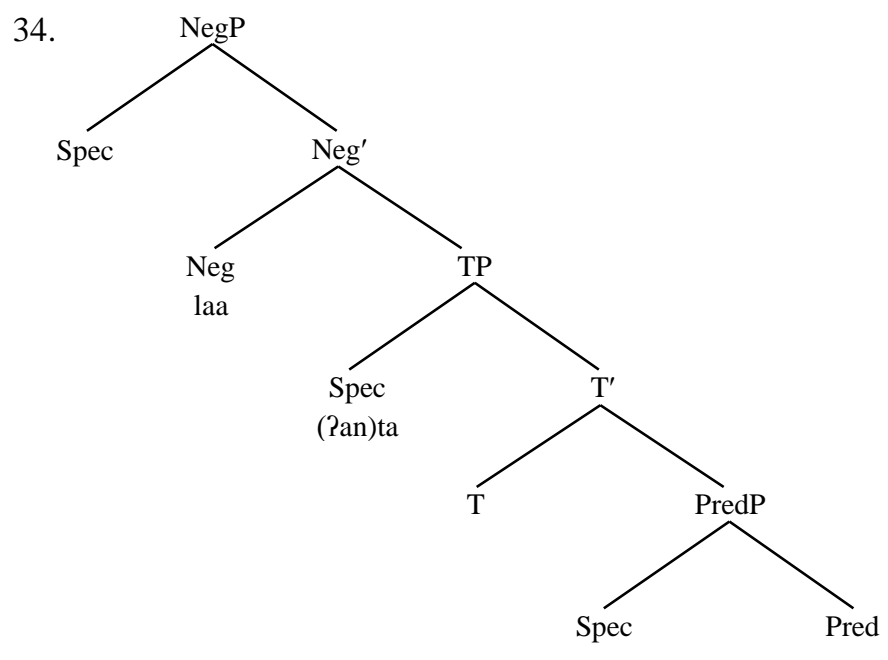

In the absence of a verbal or a tense host, the configuration in (34) is said to give rise to the negative laysa and its variants in SA. Linear adjacency between the pronoun in Spec,TP and Neg results in incorporation of the pronoun into 
the negative head. This incorporation process takes place in the post-syntactic component, which explains the various forms of the SA negative shown in the table in (35).

35. Subject pronouns and negative laysa forms in SA

\begin{tabular}{lcl}
\hline & Subject pronouns & laysa forms \\
\hline $1 \mathrm{~s}$ & Pana & las-tu \\
$1 \mathrm{pl}$ & nahnu & las-naa \\
$2 \mathrm{~ms}$ & Panta & la-sta
\end{tabular}

Benmamoun et al. (2014) further argue that the analysis of laysa can equally be extended to negative pronouns in the modern Arabic dialects. Present tense verbless sentences in Arabic dialects display a similar pattern to the one found in $\mathrm{SA}$ in that it consists of the subject and a predicate without a copula. Although the negation patterns are not the same, Benmamoun et al. argue that the derivation of negative pronouns in the dialects is identical to that of the SA negative laysa. Consider, for instance, the derivation for the JA negative pronoun ma-huu-f, represented in the following structure.

36.

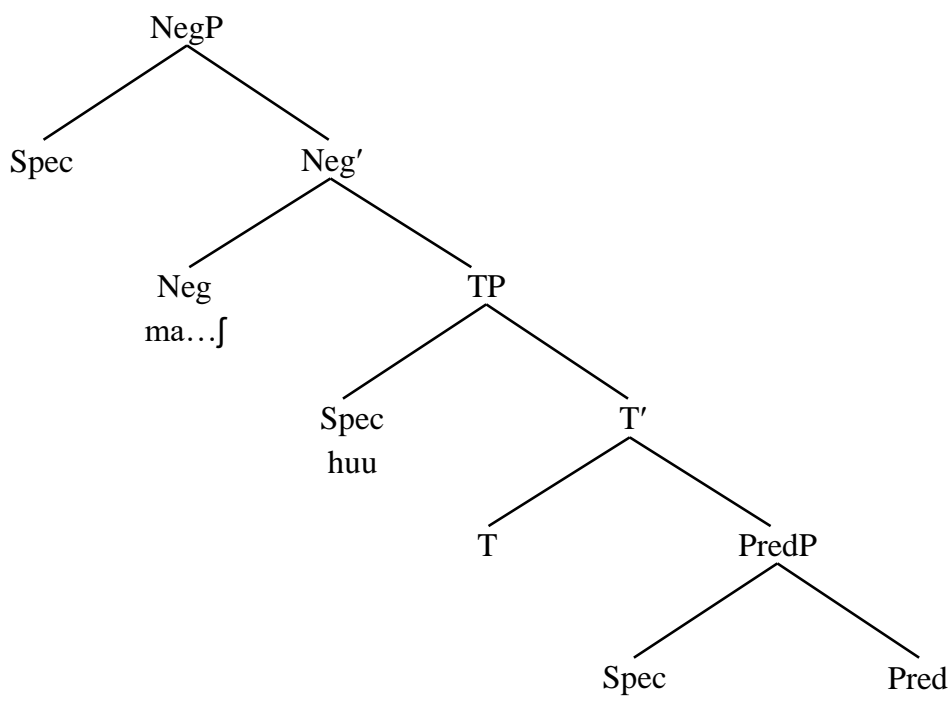

In this structure, the pronoun huu 'he' is in Spec,TP which is immediately below the negative head ma ... . After all syntactic operations have taken place, the pronoun incorporates into the split negative marker ma ... . Accordingly, this post-syntactic operation results in the formation of the negative compound ma-huu- $\int$. Other negative pronouns in the dialects are also assumed to be derived in the same way.

Although the incorporation analysis proposed in Aoun et al. (2010) and Benmamoun (2014) appears to be on the right track, it still needs further refinement in many aspects. On the one hand, the claim that subject pronouns incorporate into the negative head post-syntactically in the dialects on a par with SA laysa is problematic. In addition to the morphological difference between the SA negative laa and the discontinuous negative ma.... in the dialects, incorporation of the subject pronoun and the negative head yields the NEG-PRON-NEG pattern, not the NEG-PRON pattern found in the case of laysa. As it turns out, the NEG-PRON-NEG pattern is common in other dialects beside JA. Consider the following Egyptian Arabic (EA) and Moroccan Arabic (MA) examples.

$$
\begin{aligned}
& \text { 37a. il-mudarris ma-huwwa-š latiif } \\
& \text { the-teacher NEG-he-NEG nice } \\
& \text { 'The teacher is not nice.' } \\
& \text { b. inta ma-nta-š mudarris } \\
& \text { you NEG-you-NEG teacher } \\
& \text { 'You are not a teacher.' }
\end{aligned}
$$
b. inta ma-nta-š mudarris you NEG-you-NEG teacher

38a. Omar ma-huwwa-ši mrid. Omar NEG-he-NEG sick

'Omar is not sick.'
b. ma-niš mn hna
NEG-1s-NEG from here'
'I am not from here.'

(EA: Eid 1992)

(MA: Ouhalla 2002)

(MA: Brustad 2000)

On the other hand, there are attested patterns in another group of dialects whereby the subject pronoun surfaces as a clitic attached to negation on a par with SA laysa. In addition to the Gulf Arabic (Holes 2004) negative pronouns $m$ - $u u$ 
(NEG-3ms)/m-ii (NEG-3fs), San'ani Arabic (Benmamoun and Al-Asbahi 2014) and Hijazi Arabic (Al Zahrani 2015) negative pronouns display this pattern too, as can be seen in the table provided below.

39. Negative pronouns in San'ani Arabic

Negative pronouns in San'ani Arabic

$\begin{array}{ll}\text { Neg-1s } & \text { miš-ana } \\ \text { Neg-1pl } & \text { miš-eћne } \\ \text { Neg-2ms } & \text { miš-ant }\end{array}$

In JA, the order NEG-PRON also occurs in verbless constructions except that in JA the pronoun does not incorporate into negation. In the following sentences, the pronoun follows the negative and does not merge with it.

\author{
40a. 1-mudeer mis huwwa 1-mas?ool \\ the-principal NEG he the-responsible \\ 'The principal is not the one responsible.' \\ b. l-banaat mis hinne Sahbaat l-qaraar \\ the-girls NEG they.3fpl owners the-decision \\ 'The girls are not the decision makers.'
}

The facts from San'ani Arabic, Gulf Arabic and JA indicate that negative pronouns pattern with SA laysa in that the negative precedes the pronoun but does not surround it. In this respect, the analysis outlined for laysa above can be straightforwardly extended to San'ani and Gulf Arabic negative pronouns, as argued for in Benmamoun et al. (2014). The NEG-PRON pattern that these dialects display results from an enclitization process involving the subject pronoun in Spec,TP and the negative head directly above it. In JA, however, the pronoun in Spec, TP does not incorporate into negation, which can be attributed to the discourse properties that such constructions are associated with. The point that can be made here is that the analysis proposed in Benmamoun et al. neatly accounts for the NEG-PRON pattern found in SA, GA, San'ani and Hijazi Arabic, but not the NEG-PRON-NEG pattern found in JA, EA, and MA. The next section puts forward a more adequate analysis for the JA pattern based on new facts about the morpho-syntactic properties that such pronouns have.

\title{
4. A morpho-syntactic analysis of negative pronouns
}

The data examined so far reveals that there are two patterns of negative pronouns found in Arabic dialects. One pattern involves the sequence NEG-PRON found in SA and the Gulf Arabic varieties, including San'ani and Hijazi Arabic. The other pattern of negative pronouns is the one found in Jordanian, Egyptian and Moroccan Arabic, namely, the NEGPRON-NEG pattern. In the previous section, I have demonstrated that the incorporation analysis of SA laysa (Aoun et al. 2010, Benmamoun et al. 2014) can be extended to the NEG-PRON pattern in San'ani, Hijazi and Gulf Arabic. In this pattern, the subject pronoun appears in its reduced form as a clitic attached to the negative particle maa in the dialects and the negative particle laa in SA. The formation of this pattern results from a post-syntactic encliticisation process. The subject pronoun in Spec,TP attaches to the Neg head above it. On the other hand, the incorporation analysis fails to adequately capture the NEG-PRON-NEG pattern in JA, EA, and MA. It was concluded that a more appropriate analysis for the JA pattern is called for.

In order to properly account for NEG-PRON-NEG pattern, we must examine whether the language displays patterns that are similar to it and, if so, see what gives rise to such patterns. As might be recalled, past and present tense sentences are negated via the discontinuous strategy whereby the verb appears surrounded by the two negative elements in the sequence NEG-V-NEG. This pattern results from verb movement to the negative head that takes place in the syntax. In negative pronouns constructions, too, the pronoun appears surrounded by the discontinuous negative just like the verbs in past and present tense sentences. The resulting NEG-PRON-NEG pattern is also similar to the NEG-VNEG pattern. These similarities suggest that we approach negative pronouns in the same way as their verbal counterparts. Let us then proceed with the assumption that negative pronouns result from movement of the pronoun to the negative head and that this movement must be head movement that takes place in the syntax.

Analytically, negative pronouns occur in present-tense constructions where there is no verb to raise to the negative. This leaves the uninterpretable $[+\mathrm{D}]$ feature of the negative head unchecked. In the absence of a verbal checker, this means that categories carrying this feature are potential candidates for the checking of the $[+D]$ feature of Neg. Bearing in mind that the $[+D]$ feature is the person feature (Ritter 1995, Benmamoun 2000, and Mohammad 2014), subject pronouns are clearly able to perform this checking. This can be attributed to the feature makeup of pronouns, particularly the person feature ${ }^{\mathrm{x}}$. If we are to maintain the assumption that negation involves head-movement, the problem that we have to deal with, then, is to do with the syntactic status of the subject pronoun. More than one alternative can be suggested to overcome this problem. We can simply assume that the merger between the pronoun and other categories with negation takes place in the post-syntactic component as originally suggested in Aoun et al. (2010), 
Soltan (2014), and Benmamoun et al. (2014). This way the syntactic restriction on head-movement is neutralized. However, this alternative runs into problems surrounding the morphology and syntax of such constructions, especially when we consider other negation facts under this alternative. Morphologically, the problem is that encliticisation in this instance yields attested patterns in other varieties that differ from the pattern under study; a problem that we tried to avoid in the first place. Syntactically, on the other hand, the problem that this alternative gives rise to concerns the checking of the uninterpretable [+D] feature of Neg. Under a post-syntactic analysis, it is not clear how or even whether this checking takes place.

The other alternative is to assume that subject pronouns and other XP categories incorporating into the negative head behave as XPs for Case and theta-role assignment and as heads for movement. Such an alternative is not novel and is reminiscent of the situation of Romance clitics. Clitic pronouns in Romance have always posed a challenge for analyses built on the standard assumptions for phrase and head movement. Syntactically, clitics are clear maximal projections in the position where they are generated. Nevertheless, clitics end up being merged with lexical and inflectional heads. To account for the dual character of Romance clitics, Kayne (1989) proposes a solution whereby clitic pronouns originate as phrases but undergo movement and adjoin as heads. The advantage such alternative has is that it provides a more promising perspective for solving the case of negative pronouns. In fact, closer examination of the forms that subject pronouns take in JA supports this alternative. The data reveals that there are two forms for subject pronouns in JA: strong/emphatic forms that are freestanding and weak forms that are bound. These are shown in the following examples.

$$
\begin{aligned}
& \text { 41a. rawwah-u hummu w wlaad-hum } \\
& \text { left-3mpl they.3mpl and children-their.3mpl } \\
& \text { 'They and their children left.' } \\
& \text { b. sme3na inna-k za3laan } \\
& \text { heard-1pl that-2ms upset } \\
& \text { 'We heard that you were upset.' } \\
& \text { c. sme3na inna-k Pente za3laan } \\
& \text { heard-1pl that-2ms you upset } \\
& \text { 'We heard that you were upset. }
\end{aligned}
$$

The two forms of subject pronouns are syntactically different, as can be seen in the sentences above. Sentence (41a) involves both forms of the subject pronoun: the weak bound form $-u(3 \mathrm{mpl})$ and the independent form hummu (they.3mpl). Likewise, (41c) involves the weak bound form $-k(2 \mathrm{~ms})$ and the strong independent form ?ente (you.2ms). In both sentences, the independent form of the pronoun doubles the weak form and gives the sentence an emphatic reading. Hence, such forms are not likely to be arguments. Instead, they are best analyzed as focus elements. What directly concerns us here is the weak forms of subject pronouns. Given the contrast between the two forms, it is natural to assume that weak subject pronouns are DPs occupying the external argument position. Since they are bound, such pronouns must head move from their original position and adjoin to the lexical heads that bind them.

The distinction made between the class of strong non-argumental pronouns and the class of weak argumental pronouns is crucial to the present analysis. The importance of this distinction lies in indicating that only weak pronouns merge into heads. It follows from this distinction, then, that negative pronouns are weak subject pronouns that are merged with the lexical head of negation. Assuming that we are on the right track, we can now account for the syntactic behavior of negative pronouns in verbless sentences. Following Fassi Fehri (1993), I take such pronouns to originate as bare D heads in the DP structure that contains them. Given that these pronouns are subjects, I assume that they originate as external arguments in the specifier position of the lexical projection containing that predicate (see Abdel-Razaq 2012). Consider the partial representation below.

42.

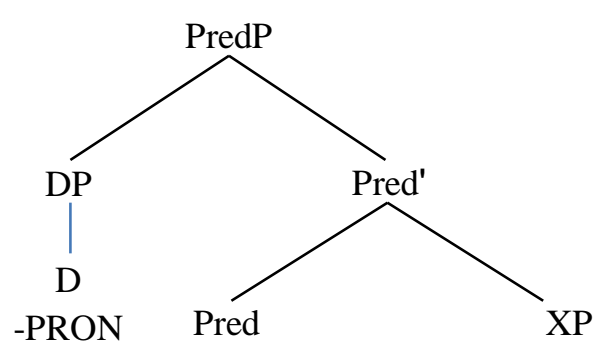

Recall that negative pronouns occur in present tense verbless sentences that have been assigned a TP structure in earlier sections of this study (see section 3.1). The position of TP has also been shown to be lower than NegP. This yields the following structural representation. 
43.

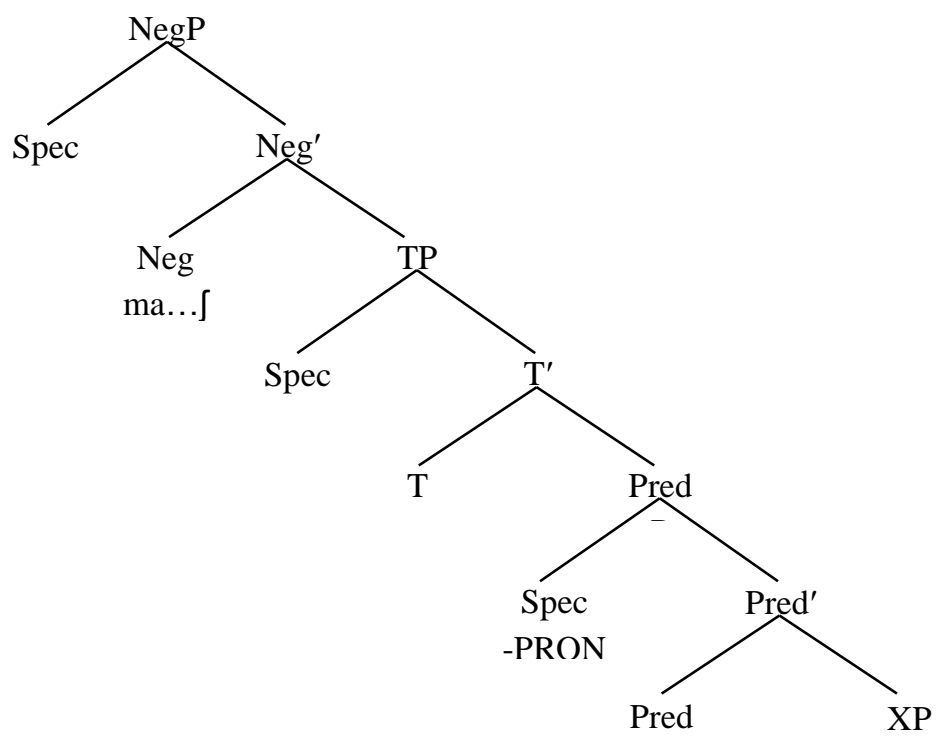

In order to account for the merger between subject pronouns and the head of negation in negative pronouns constructions, the following operations are assumed to take place. First, the subject pronoun undergoes DP movement from Spec,PredP to Spec,TP for Nominative case checking. Secondly, recall that Neg has an uninterpretable [+D] feature that needs to be checked and deleted by a matching interpretable feature. In the absence of a verbal predicate, only elements that bear the person feature can perform the checking of the categorical feature of Neg. The only candidate in the structure is the subject pronoun. Hence, the pronoun undergoes movement and adjoins to Neg. Given the present analysis, movement of the pronoun in this case takes the form of head movement, namely as a D element. As for the EPP property of Neg, it is satisfied through the Spec-head relation with Neg taking into account that Neg is now a complex head containing the negative and the subject pronoun. Altogether, the structural representation that might be assigned for negative pronouns constructions like (44a) is shown in (44b) below.

$$
\begin{aligned}
& \text { 44a. Pente ma-ntii- } \int \quad \text { Deif } \\
& \text { you NEG-you-NEG guest } \\
& \text { 'You are not a guest.' }
\end{aligned}
$$

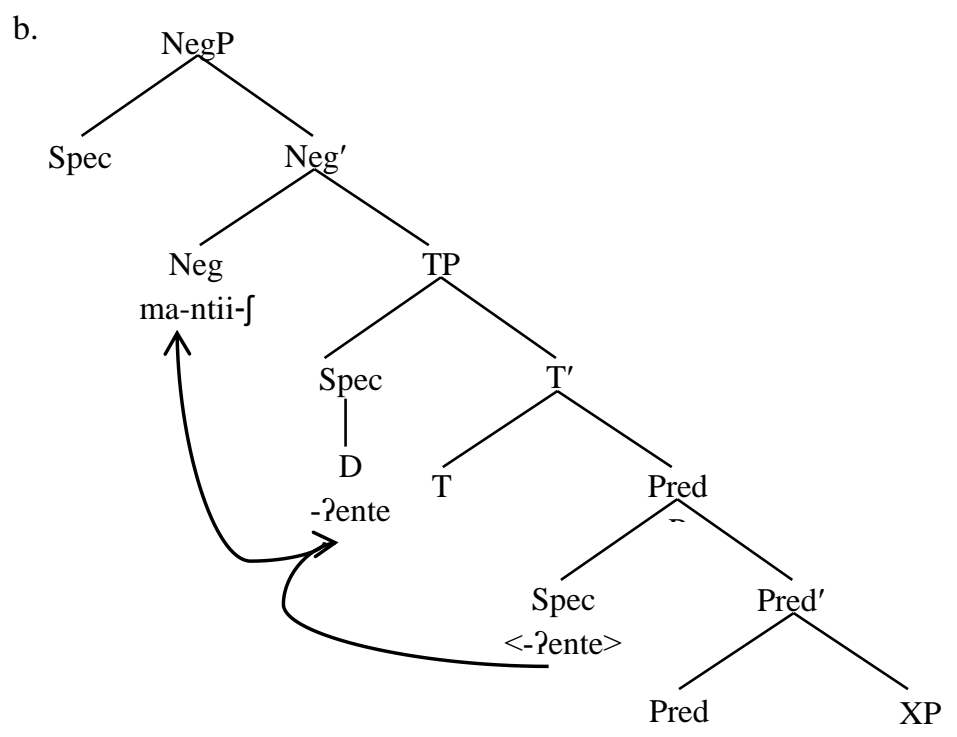

It is noteworthy here that head movement of the pronoun to Neg ensures that the pronoun is morphologically supported by the lexical material in Neg. That the pronoun needs a lexical host follows from its nature as a bound pronoun. Moreover, the path of movement that the pronoun undergoes is similar to the one found in verbal sentences in which the verb undergoes movement from $\mathrm{V}$ to $\mathrm{T}$ and then to Neg, thereby forming the NEG-V-NEG pattern. In the case of pronouns, the pattern produced is NEG-PRON-NEG. The next section continues with this analysis and how it affects the overall structure in which negative pronouns occur. 


\section{Negative pronouns constructions}

The analysis provided in the previous section dealt with negative pronouns, particularly their merger with negation, but not with the whole construction in which such pronouns occur. I have shown that such pronouns are subjects of a lower predicational construction within the structure of sentences that contain them. This raises the question about the status of the initial DP in negative pronouns constructions as well as the overall structure of such sentences. Studies dealing with the negative pronoun phenomenon have always overlooked such a question (Benmamoun 2000, Ouhalla 2002, AlMomani 2010, Benmamoun et al. 2014, and Soltan 2014). This section attempts to provide a syntactic analysis for negative pronouns constructions. In doing so, I bring the discussion to the point with which this study started, i.e., the apparent optionality in the distribution between the two negation strategies in verbless sentences. The relevant examples are repeated in (45-46) below.

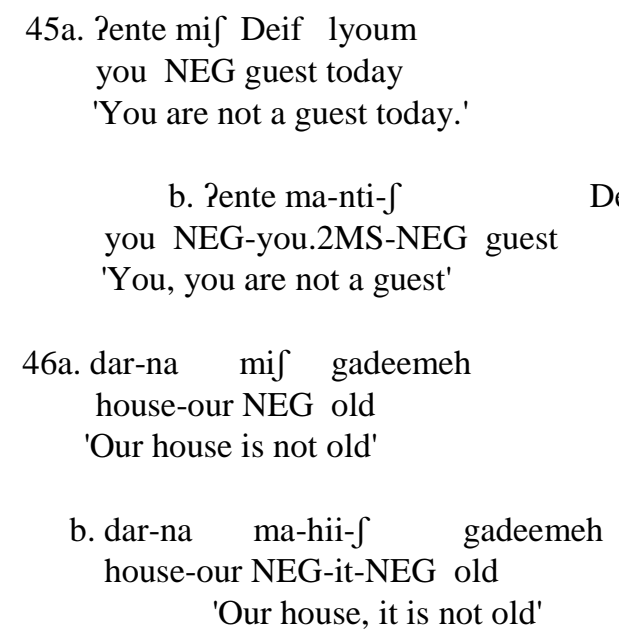

The two sets of examples above cannot be said to be the same, at least syntactically. The fact that in each set a different negation strategy is used is evidence that the two sets represent different types of construction. The second set is more complex due to the presence of subject pronouns. Given the current analysis and granting that the pronoun merging with negation is the subject in this type of construction, the co-existence of the left-most DP and the subject in the same construction must be accounted for. To do so, let us examine the properties associated with this DP. There are two crucial properties that make such DPs distinct, namely definiteness and full agreement with the subject pronoun inside the sentence. These properties are characteristic of the topic-comment construction in Arabic. In such constructions, the initial DP, namely the Topic (traditionally known as Mubtada?, i.e., something to start with) is a person or an object that is well-known and shared between the interlocutors. Consider the following examples from JA, Lebanese Arabic, and SA, respectively.

$$
\begin{aligned}
& \text { 47a. l-sayyara befet-ha mbaarih } \\
& \text { the-car sold.1S-it yesterday } \\
& \text { 'The car, I sold it yesterday.' } \\
& \text { b. *sayyara befet-ha mbaarih } \\
& \text { the-car sold.1S-it yesterday }
\end{aligned}
$$

48a. hayda l-ktiib Pariit-u b-nhaar this the-book read.1s-it in-day 'This book, I read it in a day.'

$$
\begin{aligned}
& \text { b. *ktiib Pariit-u b-nhaar } \\
& \text { this the-book read.1s-it in-day }
\end{aligned}
$$

49a. Pal-kitaab-u qara?a-hu Zayd-un the-book-Nom read.3ms-it Zayd-Nom 'The book, Zayd read it.'

b. *kitaab-un qara?a-hu Zayd-un book-Nom read.3ms-it Zayd-Nom
(LA: Aoun et al. 2010:195)

(SA: Fassi Fehri 1993)

Topic-comment sentences, or the so-called Clitic Left Dislocation (CLLD) constructions within recent linguistic theory (Aoun and Benmamoun 1998, Soltan 2007, Aoun et al. 2010, and Abdel-Razaq 2012), are common across the various Arabic dialects. In the sentences above, the left-most definite DP is treated as a topic followed by a complete predicational string that contains the pronoun, with which the initial DP is coreferential, and the predicate. Notice that 
indefinite nonspecific DPs cannot occur in the left-most position in this type of construction in Arabic as shown by the ungrammaticality of the (b) examples.

In terms of sentential negation, topic-comment sentences are negated via the discontinuous strategy. Recall that this strategy involves merger of the verb and the discontinuous negative in the pattern NEG-V-NEG. Consider the following examples from JA.

$$
\begin{aligned}
& \text { 50a. 1-sayyara ma-beSet-ha- } \int \text { mbaarih } \\
& \text { the-car NEG-sold.1S-it-NEG yesterday } \\
& \text { 'The car, I did not sell it yesterday.' } \\
& \text { b. *sayyara ma-beSet-ha- } \int \text { mbaarih } \\
& \text { the-car NEG-sold.1s-it-NEG yesterday } \\
& \text { c. *l-sayyara mif beSet-ha mbaarih } \\
& \text { the-car NEG sold.1s-it yesterday }
\end{aligned}
$$

Out of the three sentences above, only (50a) is acceptable. (50b) is ruled out because of the definiteness restriction on topic DPs in Arabic. Notice that negation does not improve the status of the sentence. Meanwhile, (50c) is ruled out because the independent negation strategy is used instead of the discontinuous verbal strategy. Semantically, the initial DP in all the acceptable cases above has the same interpretation as the topic of discourse against which the event is presented, regardless of whether or not the event is negated. In other words, negation does not affect the topicality status of the initial DP, and indeed of the whole construction.

The other property that has not been mentioned earlier but is worth considering here is Case. Topics in Arabic typically bear default Nominative case (see Aoun et al. 2010 and the references cited therein) due to the absence of structural or lexical Case assigners. The sentences from SA above clearly show that topic DPs bear the Nominative case. The same also holds for the dialects though Case is not overtly shown due to historical evolvement of the dialects resulting in morphological loss of Case endings.

The properties associated with topic-comment constructions above are also characteristic of negative pronouns constructions. As might have been observed, in those constructions the initial DP is definite and is coreferential with the subject pronoun inside the predicational clause. The examples in (51) show that indefinite DPs cannot occur in negative pronouns constructions, whereas the ones in (52) show that lack of full agreement between the initial DP and the subject pronoun renders the sentences unacceptable.

$$
\begin{aligned}
& \text { 51a.*zalemeh ma-hu- } \int \text { Deif } \\
& \text { man NEG-he-NEG guest } \\
& \text { b. *dar ma-hii- } \int \text { gadeemeh } \\
& \text { house-our NEG-3fs-NEG old } \\
& \text { 'Our house, it is not old' } \\
& \text { 52a. *?ente ma-hu- } \int \quad \text { Deif } \\
& \text { you NEG-3ms-NEG guest } \\
& \text { b. *dar-na ma-hu- } \int \text { gadeemeh } \\
& \text { house-our NEG-3ms-NEG old }
\end{aligned}
$$

As for Case properties, the initial DP in negative pronouns constructions in the dialects is also assumed to bear the Nominative Case, though not overtly. This can be discerned from SA verbless topic-comment constructions like (53) below in which the topic evidently bears the Nominative Case, just like the cases in the verbal topic-comment sentences above.

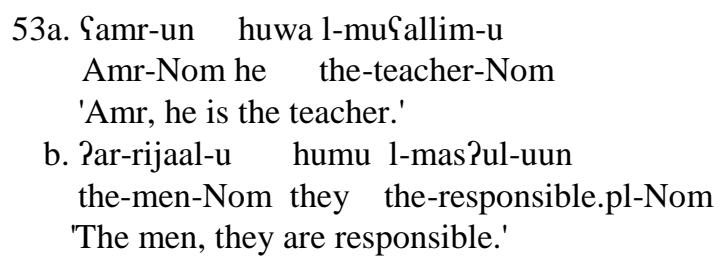

In terms of discourse properties, the initial DP is also a discourse topic about which interlocutors share previous knowledge. In other words, such constructions involve presupposition that is not found in their counterparts. Topicality here can be attributed to the semantic property of definiteness as well as the coreference relation between the DP and the subject pronoun inside the sentence. 
Based on the observations above, we can safely conclude that negative pronouns constructions represent sentential negation in topic-comment or (the more recent) CLLD constructions. In all of these constructions, the initial DP is the discourse topic followed by a complete string of predication that includes a subject and a predicate.

Structurally, topic-comment constructions are best treated as topicalisation structures. The DP topic is base-generated in the specifier position of a TopP (see Rizzi 1997). The fact that topics are definite can be taken as evidence for the basegeneration analysis. A movement analysis cannot explain why only definite DPs can move to the left peripheral position while indefinite DPs cannot ${ }^{\mathrm{xi}}$. In negative pronouns constructions, the DP topic is followed by the negative pronoun and the predicate. Under the analysis developed in this study, NegP is higher in the structure than TP. The overall structure for negative pronouns constructions like (54a) can be roughly represented in the simplified structure in (54b) below.

$$
\begin{aligned}
& \text { 54a. Pente ma-ntii- } \int \quad \text { Deif } \\
& \text { you NEG-you-NEG guest } \\
& \text { 'You are not a guest.' }
\end{aligned}
$$

b.

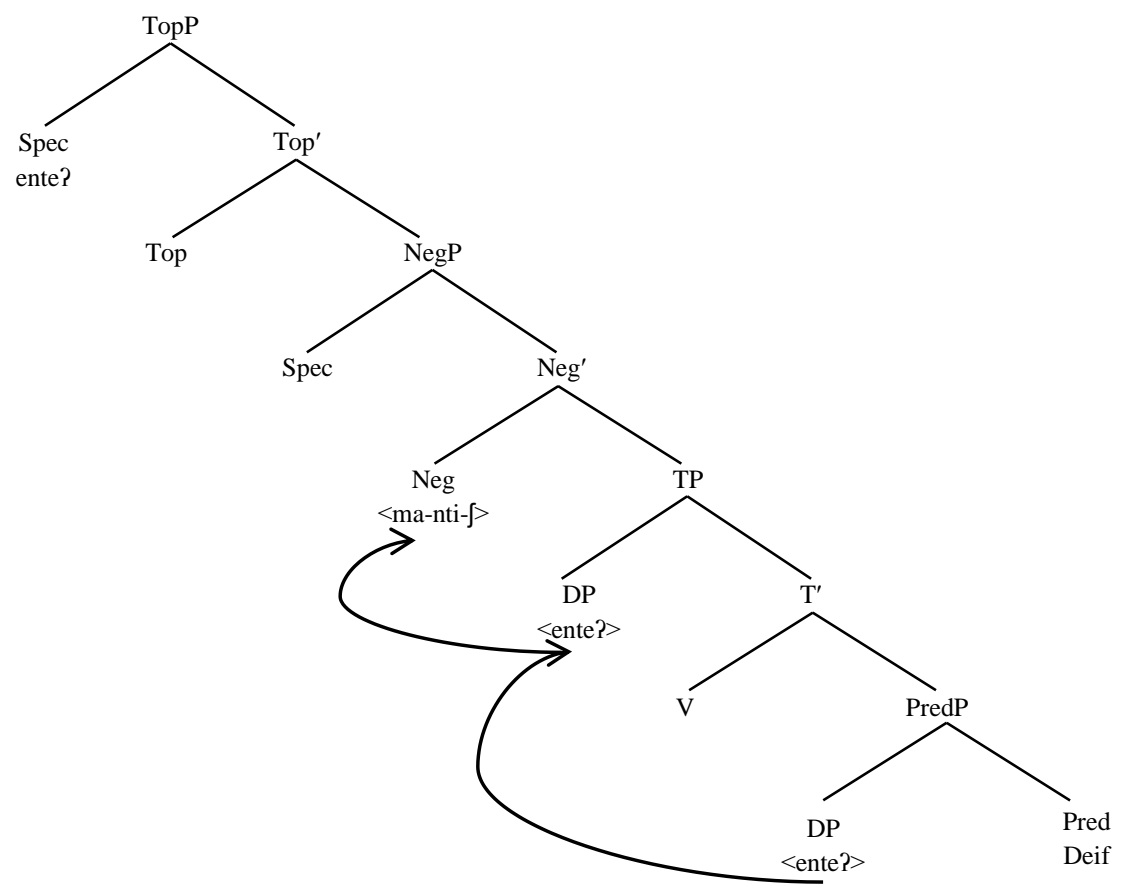

Within the present analysis, the structure in (54b) captures all the facts presented so far from negative pronouns constructions. It explains the presence of a DP along with the subject in such constructions by assigning them a topicalisation structure. The initial DP is a base-generated topic followed by the comment that constitutes the (negative pronominal) subject and the predicate. It also accounts for the occurrence of the subject pronoun and its merger with negation, as we have seen in the previous section.

Treating negative pronouns constructions as topicalisation structures solves the problem of optionality of negation in verbless sentences that this study raised at the outset. The unmarked negation strategy in verbless sentences is the independent strategy. When such constructions are tropicalized, the marked negation strategy, i.e., the discontinuous strategy, is used. Thus, it is not the case that either negation strategy can be used in verbless sentences. The choice of which negation strategy to use cannot be settled by purely syntactic means, discourse factors come into play too. Whereas the independent negation strategy is the neutral strategy used in contexts where no previous information is necessary, the discontinuous strategy is used when emphasis is placed on the topic DP and against a negated predication.

\section{Conclusion}

This study has been mainly concerned with the distribution of negation strategies in verbless sentences in Jordanian Arabic. I have shown that although the type of negation strategy is linked to the type of sentence in which it occurs, i.e., whether verbal or non-verbal, there is one construction that cuts across this typological division. Negative pronouns constructions are verbless constructions that involve the use of the discontinuous negation strategy of verbal sentences. What is also interesting about these constructions is that pronouns behave like verbs in that they merge with negation and show full agreement with the initial DP. Several questions have been raised about the syntactic status of pronouns, the use of the verbal negation strategy in a verbless construction, and the status of the whole construction in which such pronouns occur.

To answer these questions, the study started with an analysis adopted from the work of Benmamoun (2000) and Aoun et al. (2014) for the syntax of sentential negation in verbal sentences in JA. It has been shown that while the adopted analysis accounts for negation facts in past and present tense sentences, it ran into problems in various other contexts. The original assumption that NegP is lower than TP was given up and a modified assumption whereby NegP is higher 
than TP was put forward. Building on the latter assumption, I have also argued that the subject is in Spec,NegP, not Spec,TP. Altogether, proposed analysis neatly accounted for all negation facts presented in the discussion.

The second part of this study explored negation in verbless sentences and concentrated on three issues: merger of the pronoun with negation, the nature of the construction in which negative pronouns occur, and the apparent optionality in the use of negation strategies in verbless sentences. To settle the first issue, I have demonstrated that the pronoun merging with negation is a weak subject pronoun that starts the derivation as a DP. It then undergoes movement as a bare D head and adjoins to the head of the negative projection in order to check and delete the uninterpretable [+D] feature of Neg, hence the merger between the pronoun and negation. Concerning the second issue, the analysis proposed for negative pronouns also accounted for the syntax of the overall construction in which they occur. Closer examination revealed that negative pronouns constructions represent sentential negation in topic-comment or (the more recent) CLLD constructions that involve a fronted DP and a complete predicational string with the subject and the predicate. Therefore, the structure that has been assigned to negative pronouns constructions was a standard Top(icalisation) structure that captured all the facts from these constructions.

Treating negative pronouns constructions as topic-comment structures has also solved the optionality problem. Such constructions are found in contexts associated with certain discourse properties amongst which is presupposition on the part of the interlocutors. Hence, the initial DP in such construction is semantically interpreted as a topic of discourse against which the event is presented. Such properties necessitate the use of the marked strategy of negation in JA. Whereas, in standard contexts that do not involve presupposition, the unmarked negation strategy is used. This way, optionality is understood as two types of constructions each of which is associated with certain syntactic and semantic properties that distinguish it from the other. It remains to be seen, however, whether the proposed analysis extends to the other dialects of Arabic, though the implications that this analysis has point to that direction. I leave this issue for further future research.

\section{References}

Abdel-Razaq, Issa (2012). Who Is What and What Is Who: The Morphosyntax Of Arabic WH. Cambridge Scholars Publishing. UK.

Algryani, Ali (2015). Sentential Negation in Libyan Arabic: A Generative Perspective. International Journal of Linguistics, 7(6), pp. 134-145.

Al-Horais, Nasser. (2006). Arabic verbless sentences: is there a null VP? Pragmalinguistica 14, 101-116.

Al-Momani, Islam M. (2011). The Syntax of Sentential Negation in Jordanian Arabic. Theory and Practice in Language Studies, 1(5), pp. 482-496.

Al Zahrani, Mohammad A. (2015). The Syntactic properties of negatives. US-China Foreign Language, 13(1), pp. 1-18.

Aoun, Joseph, and Elabbas Benmamoun (1998).Minimality, Reconstruction and PF Movement. Linguistic Inquiry 29, 569-592.

Aoun, Joseph, Elabbas Benmamoun and Lina Choueiri (2010). The Syntax of Arabic. Cambridge University Press.

Benmamoun, Elabbas. (2000). The Feature Structure of Functional Categories: A Comparative Study of Arabic Dialects. Oxford: Oxford University Press.

Benmamoun, E., Abunasser, M., al Sabbagh, R., Bidaoui, A., and Shalash, D. (2014). The location of sentential negation in Arabic varieties. Brill's Annual of Afroasiatic Languages and Linguistics 5, 83-116.

Benmamoun, E., Abunasser, M., al Sabbagh, R., Bidaoui, A., and Shalash, D. (2014). Variations on the Same Theme: Sentential Negation and the Negative Copula in Arabic. In Perspectives on Arabic Linguistics XXIV-XXV: Papers from the Annual Symposia on Arabic Linguistics, Texas ed. by Farwaneh, S. and Ouali, H., editors, 121-138. John Benjamin's, Amsterdam and Philadelphia.

Benmamoun, Elabbas, and Khaled Al Asbahi. (2014). Negation and the Subject Position in San'ani Arabic. In Perspectives on Arabic Linguistics XXV, ed. by Karen Froud and Reem Khamis. Dakwar. Amsterdam: John Benjamins, 2014. 75-90.

Bowers, John. (1993). The Syntax of Predication. Linguistic Inquiry ,24, 591-656.

Bowers, John. (2001). Predication. In The Handbook of Contemporary Syntactic Theory, ed. by Mark Baltin and Chris Collins. Oxford: Blackwell.

Brustad, K. (2000). The syntax of spoken Arabic. Washington, DC: Georgetown University Press.

Chomsky, Noam. (1995). The Minimalist Program. Cambridge, Mass.: MIT Press.

Chomsky, Noam. (2000). Minimalist inquiries: The framework. In Step by step: Essays on minimalist syntax in honour of Howard Lasnik, ed. by Roger Martin, David Michaels and Juan Uriagereka, 89-115. Cambridge, Mass.: MIT Press.

Chomsky, Noam. (2001a). Derivation by Phase. In Ken Hale: a life in language, ed. by Michael Kenstowicz, 1-52. Cambridge, Mass: MIT Press.

Chomsky, Noam. (2001b). Beyond Explanatory Adequacy. MIT Occasional Papers in Linguistics, 20, 1-28. MIT. 
Chomsky, Noam. (2005). Three Factors in Language Design. Linguistic Inquiry, 36, 1-22.

Cowell, Mark W. (1964). .A Reference Grammar of Syrian Arabic. Washington: Georgetown University Press.

Eid, Mushira. (1983). The Copula Function of Pronouns. Lingua, 59, 197-207.

Eid, Mushira. (1992). Pronouns, Questions, and Agreement. In Perspectives on Arabic Linguistics IV, ed. by Ellen Broselow, Mushira Eid and John McCarthy, 107-141. Amsterdam: John Benjamins.

Fassi Fehri, Abdelkader. (1993). Issues in the Structure of Arabic Clauses and Words. Dordrecht: Kluwer.

Holes, Clive. (2004). Modern Arabic: Structures, Functions, and Varieties. Washington DC: Georgetown University Press.

Kayne, Richard. (1989). Null subjects and clitic climbing. In The null subject parameter, ed. by Osvaldo Jaeggli and Kenneth Safir, 239-261. Dordrecht: Kluwer.

Kenstowicz, Michael. (1989). The Null Subject Parameter in Modern Arabic Dialects. In The Null Subject Parameter, ed. by Osvaldo Jaeggli and Kenneth Safir, 263-276. Dordrecht: Kluwer.

Mohammad, Mohammad. (2000). Word Order, Agreement and Pronominalization in Standard and Palestinian Arabic. Amsterdam: John Benjamins.

Ouhalla, Jamal (2002). The Structure and Logical Form of Negative Sentences in Arabic. In Themes in Arabic and Hebrew Syntax, ed. by Jamal Ouhalla and Ur Shlonsky, 299-320. Dordrecht: Kluwer.

Ouhalla, Jamal (2005). Agreement features, Agreement and Anti-agreement. Natural Language and Linguistic Theory 23:655-686.

Ritter, Elizabeth. (1995). On the syntactic category of pronouns and agreement. Natural Language \& Linguistics Theory $13,405-443$.

Rizzi, Luigi. (1990). Relativized Minimality. Cambridge, Mass.: MIT Press.

Rizzi, Luigi. (1997). The Fine Structure of the Left Periphery. In Elements of Grammar, ed. by Liliane Haegeman, 281-337.Dordrecht: Kluwer.

Shlonsky, Ur. (1997). Clause Structure and Word Order in Hebrew and Arabic: An Essay in Comparative Semitic Syntax. Oxford University Press.

Shlonsky, Ur. (2002). Constituent Questions in Palestinian Arabic. In Themes in Arabic and Hebrew Syntax, ed. by Jamal Ouhalla and Ur Shlonsky, 137-159. Dordrecht: Kluwer.

Simpson, Andrew and Zoe Wu. (2002). Agreement, Shells and Focus. Language ,78(2), 287-313.

Soltan, Usama. (2007). On Formal Feature Licensing in Minimalism: Aspects of Standard Arabic Morphosyntax. Doctoral dissertation. University of Maryland, College Park.

Soltan, Usama. (2014). The morphosyntax of sentential negation in Cairene Egyptian Arabic. In Perspectives on Arabic Linguistics XXIV-XXV: Papers from the Annual Symposia on Arabic Linguistics, Texas ed. by Farwaneh, S. and Ouali, H., editors, 91-120. John Benjamins, Amsterdam and Philadelphia.

\footnotetext{
${ }^{\text {i }}$ See Abdel-Razaq (2012) for discussion.

ii Evidence that present tense in Arabic does not require verb movement can indeed be obtained from verbless sentences. Recall that such sentences are present tense constructions involving $\mathrm{T}$ that does not bear the verbal feature $[+\mathrm{V}]$, hence no verb movement to $\mathrm{T}$ is necessary. As for negative sentences, $\mathrm{T}$ does not require the presence of a verb that would be attracted by negation. Likewise, present tense verbal sentences do not require the verb to move to $\mathrm{T}$.

iii See Benmamoun et al. (2014) for the arguments presented from different dialects in favor of locating NegP above TP.

${ }^{\text {iv }}$ In fact, the future tense marker in JA is identical to the verb $r a$ h 'went.3ms'. It could be the case that the future tense marker in JA and similar dialects has evolved from the verbal form.

${ }^{v}$ Notice that the negative enclitic $-\int$ does not surface on the future particle. My understanding for the absence of the $\int$ element in the future particle is to disambiguate it from the lexical verb rah 'go'. The latter when used in past tense sentences is spelled out as ma-rahi- $\int$ 'did not go' after verb movement to Neg.

${ }^{\text {vi }}$ For Instance, in wh-movement languages, the EPP property of a [+Wh] $\mathrm{C}$ is satisfied by movement of a wh-phrase to $\mathrm{Spec}, \mathrm{CP}$. Movement of a subject to Spec,TP is also another illustration of the EPP property of T in SV languages like Arabic. In both cases however, the EPP is not the sole trigger of movement of the subject to the specifier position. Movement of the wh-phase to $\mathrm{Spec}, \mathrm{CP}$ is also triggered by the $[+\mathrm{Wh}]$ feature of $\mathrm{C}$ while movement of the subject to Spec,TP is triggered by the Nom case feature of T.

vii See Soltan 2007, Aoun et al. 2010 and Al-Horais 2012 for arguments in favor of inserting a TP in the structure of verbless sentences in Arabic.

viii A similar analysis is also suggested in Shlonsky (2002) for Palestinian Arabic. That is, Shlonsky treats subject pronouns that occur in equative sentences as agreement markers on a par with Hebrew copula pronouns. This analysis
} 
cannot be maintained, however, simply because such pronouns are subject pronouns that differ from agreement markers in Arabic. For a full discussion, the reader is referred to Abdel-Razaq (2012).

${ }^{i x}$ For arguments against the agreement analysis of negative pronouns, see Aoun et al. (2010, Ch5).

${ }^{x}$ Earlier on in this study, we have seen cases where existential expletives and PPs with a pronominal clitic merge with negation, which indicates that they, too, check the uninterpretable feature on Neg. In this study, however, I will be concerned only with the case of subject pronouns.

xi This conclusion is reached independently in Aoun and Benmamoun (1998) and Aoun et al. (2010) who argue that typical CLLD constructions in Arabic are generated without movement. Their analysis is motivated by the fact that the relationship between the initial DP and the pronominal clitic is not sensitive to islands. For a detailed discussion on CLLD constructions, see Aoun and Benmamoun (1998), and Aoun et al. (2010). 